\title{
Focusing on relationships creates safety in schools
}

\section{Tom Cavanagh}

W

hat is the key to making our schools safe? Driven by policy makers reacting to media exposure of incidents of violence, particularly regarding bullying, New Zealand schools are seeking an answer to this important question.

Restorative justice provides a means of enhancing safety in schools. Restorative justice is based on a philosophy that can help schools form a new climate of safety. It offers more than a set of practices (i.e., conferencing, mediation, and circle time). Howard Zehr, ${ }^{1}$ recognised as a major restorative justice pioneer (Braithwaite, 2001), explained that restorative justice is defined as a response to wrongdoing and conflict that focuses on healing the resulting harm to relationships (Zehr, 2002). Healing the harm to relationships is a key concept in this study and refers to the need to respond to any behaviours that interfere with building or maintaining healthy relationships in such a way that the dignity of the individuals involved is respected.

In order to reduce bullying, fighting, and intimidation in schools and create a climate of safety, Margaret Shaw (2002) of the International Centre for the Prevention of Crime (ICPC) said we must adopt comprehensive, whole-school approaches that emphasise nonviolent responses to conflict and wrongdoing and focus on creating a school culture of safety. So what does that climate look like?

\section{Theoretical framework}

This article is placed within the theoretical framework of restorative justice. The concept of restorative justice originated within the legal system (Zehr, 1995), contrasting the retributive legal system with the restorative alternative. As a result, practitioners training school personnel about the application of these principles in schools base their training on practices used in the legal system, focusing on conferencing
(Cameron \& Thorsborne, 2001). The application of these principles generally revolves around the use of conferencing in schools as an alternative to more punitive measures (i.e., detentions, stand downs, suspensions, and exemptions).

What these well-intended approaches lack is a perspective from inside education about the application of the restorative justice philosophy in schools. This perspective is important because the legal system uses conferencing to make the wrong right, generally between individuals who do not have a personal relationship. In schools the centre of focus has to be healing broken relationships, particularly between students causing harm and their teachers and peers who are harmed.

My research focuses on the culture of schools, addressing the question: How do restorative practices (The Restorative Practices Development Team, 2004) affect the culture of schools, particularly related to a culture of peace and nonviolence? I am an insider in both the legal system and schools, having worked as a court reporter for 30 years in American courts and more recently completing my doctoral work and conducting research in education. Thus, I bring those perspectives to the application of restorative justice principles to schools.

The theoretical framework for this study is life giving and hopeful, giving agency to students, parents, teachers, school administrators, and community members. Such an approach deconstructs the traditional theoretical frameworks that promote technical responses and proposes a holistic, life-giving model for responding to wrongdoing and conflict in schools. Schools are a unique environment, and the application of restorative justice principles in the school environment necessitates application by those who understand the unique character of schools. 


\section{Methodology}

The research project that forms the basis of this paper was conducted as part of a Fulbright Fellowship. A New Zealand area school was chosen for this case study because staff were undergoing professional development in the area of restorative practices. I deliberately chose to live in the community where the school was located so I could get to know the students, their families, and staff both in the school and the community as I went about daily living.

The question that drove this study was: How do we create a school climate of safety? I chose to do an ethnography (a holistic research method based on the idea that schools need to be studied as a system) because it is appropriate for studying the culture of schools. I wanted to learn about the daily-lived experiences of staff and students in the school.

I began working at the school collecting the data for this project on 26 July 2004. I spent over 400 hours at the school over a period of a year because spending an extended period of time in the field is characteristic of an ethnography (Creswell, 1998).

I collected data in the form of: about 250 pages of field notes; informal, formal, and focus group interviews with students, staff, and parents; about 150 documents; and about 180 pages of journal entries. I analysed these data using constructivist grounded theory (Charmaz, 2000) and vignette writing (Van Maanen, 1988) as methods, and shared reflective memos with the participants seeking their comment. These two methods of analyses were utilised to add trustworthiness to the project.

I deliberately chose to be a participantobserver during this study. I tried to be constantly aware of my position on the continuum of observer and participant, realising that my role at the school was constantly changing (Heshusius, 1994). Maintaining ethical reciprocal relationships with the participants in the research was the foundation of validity for the study.

I did not want to assume a role of authority or power at the school so that I could develop friendships with staff, students, and parents during the natural ebb and flow of life at the school. The purpose of developing these friendships was to mediate the power relations inherent in teacher-student relations. One of the primary reasons I was committed to spending a long time in the field was to let the friendships evolve naturally to the point where there was a relationship of trust. At that time I felt I could talk with members of the school at a deep level (Tillman-Healy, 2001) that was authentic and real.

These ideas were the foundation for how I collected data during my study and how I analysed that data. The process I facilitated was participatory and designed to reconstruct the voices of the participants in a way that they would be heard and valued.

\section{Findings}

Analysis of the data collected for this project revealed three dominant themes:

- Building healthy relationships in schools is at the heart of creating a climate of safety.

- The use of restorative practices can help build a safe climate by healing the harm to relationships resulting from wrongdoing and conflict.

- A new school climate based on the principles of restorative practices will help create a culture of healthy relationships.

Further, the findings revealed there are three primary domains within this climate of safety:

- Restorative practices: "Although they are rough around the edges, in their hearts the students do care." (Teacher)

- Relationships-based pedagogy in classrooms: One staff member's philosophy of teaching: "Children want to learn, so find out what they want to learn and remove the barriers to their learning. Keep them safe."
- A culture of care: "We would love you to tell all the tamariki (children) ... they showed excellent manaakitanga (caring) to everyone through their waiata and haka. The school truly reflects our community and whānau by ... biculturalism and whanaungatanga (building relationships) strengths ... you are a great example to heaps of schools around Aotearoa." (Former teacher)

Building healthy relationships is at the core of a climate of school safety, and the three domains exist in a feedback loop of interdependence (see Figure 1).

Further analysis of the data revealed a detailed description of each of these domains.

\section{Restorative practices}

Rather than using restorative practices as another tool, in this climate of school safety, understanding the philosophy of restorative justice is the basis for determining discipline policies. In this way, the emphasis is on ensuring students continue to attend school. Through restorative practices the capacity of students and teachers is improved resulting in:

- creating safe and peaceful schools (for students and teachers)

- preparing young people for participation in society by helping them learn to solve problems and respond to conflict nonviolently.

\section{Climate of School Safety}

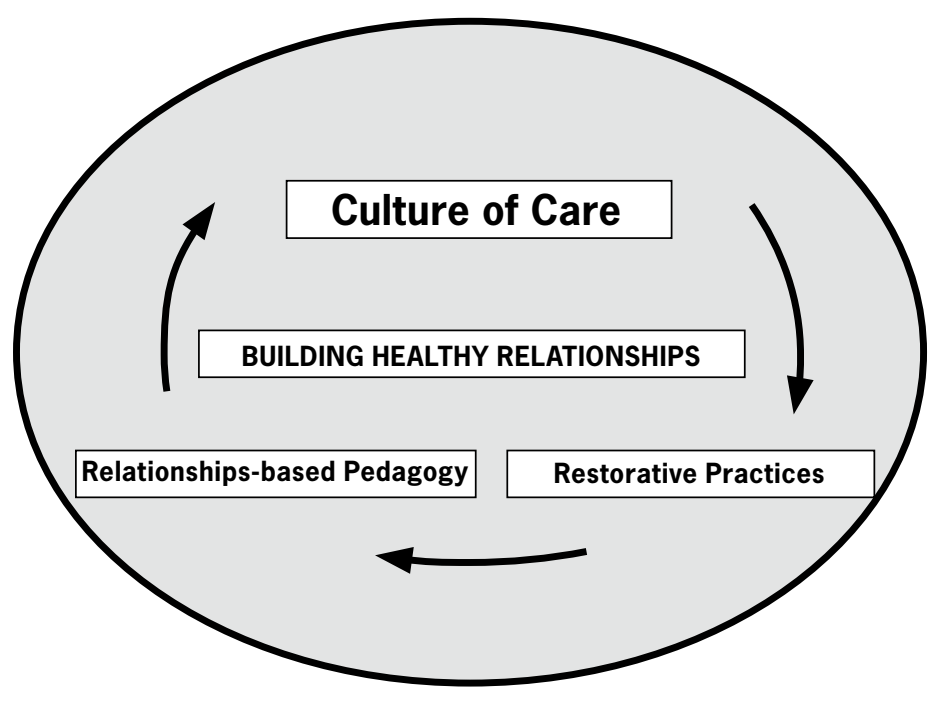




\section{Relationships-based pedagogy}

Once students' attendance has improved, engaging them in the classroom helps to repair broken relationships. Teacher pedagogies focused on relationships motivate students to be engaged and to achieve. Relationships-based pedagogy is based on:

- reciprocal relationships based on teachers and students teaching and learning together

- mutual respect

- family or whānau classroom environment where problems are understood and responded to in the classroom as a group so that the response is inclusive of all students, especially the persons causing the harm, as well as the persons harmed

- problems with student behaviours viewed as learning opportunities (not disruptions) for how to repair broken relationships.

\section{Culture of care}

The culture of care creates a bond between restorative practices and relationships-based pedagogy by providing consistency throughout the school and contributing to whole-school reform. The school needs to support a culture of care by employing strategies such as:

- rituals, traditions, and stories focused on building relationships rather than division and competition

- sense of community and solidarity or all-for-all, so that every person feels they belong

- putting relationships at the core of the mission and vision of the school rather than curriculum.

\section{Summary of findings}

This ethnographic research study revealed that if restorative practices are to be focused on healing the harm to relationships they will necessarily require the inclusion and participation of the person(s) harmed and the person(s) causing the harm. Normally these persons know each other and will continue to have a relationship in the future. Restorative practices must include all persons affected by the wrongdoing or conflict. If a student is sent outside of the classroom to an administrator or an "expert" to solve a problem, the people in the classroom (students and teacher) are robbed of the opportunity to build their capacity to respond nonviolently to conflict and wrongdoing and to be nonviolent, selfsustaining adults.

Taking a student out of the classroom because of "bad behaviour" and asking someone outside the classroom to address these problems is an exclusionary practice. Although the intention is to let the teachers and students in a classroom go on without interruption, in the end this process does not address the harm to relationships resulting from the behaviour. Later when the student is returned to the classroom, without addressing the harm he or she has caused to relationships, these relationships keep on breaking down without healing.

Building and maintaining respectful relationships is a key part of the role of an effective teacher. The research showed the end result often is that students are being stood down because they have no positive relationships in the school. Thus, the adults in the school have an obligation to help these students heal broken relationships (with other students and teachers) because healthy relationships are the key for success in schools.

At the school-wide level, restorative practices focus on building healthy relationships through conversations and behaviours, and restoring the dignity of the individuals involved and the group (class and school) through the healing of broken relationships. The work of experts or practitioners in restorative practices is to build the capacity (knowledge, skills, and experience) of students and teachers in this regard.

\section{Implications for students, teachers, and schools}

\section{Students}

Students need to be encouraged and supported to increase their capacity to respond to conflict and wrongdoing nonviolently. In fact, when behaviour problems are solved for them, students are robbed of the opportunity to learn valuable skills for living in peaceful relationships.

Building this capacity in students involves many skills that can be acquired over time as appropriate to the age of the child. Based on this study and earlier research, I recommend that the skills students need to have and at what age are:

- Understanding feelings (ages 5-6) by helping students learn that as an individual I have feelings, and you have feelings, and our feelings may or may not be the same. Most importantly, children need to learn about empathy as bonding with another individual in such a way as to appreciate at a deep level how they are feeling.

- Building friendships (ages 7-9) by understanding the dynamics of belonging to a group and learning about listening, trusting, speaking honestly and from the heart, and being respectful of others. Key skills to learn at this age are negotiation and mediation.

- Developing peacemaking circles (ages 10-11) by being encouraged and learning how to call and lead a peacemaking circle and use a talking stick as a tool (Pranis, Stewart, \& Wedge, 2003) to help solve problems among a group of students.

- Engaging in restorative conversations (ages 12-14) by learning how to hold conversations with others where the problem has been separated from the person.

- Facilitating restorative conferences (ages 15-17) by learning the process of facilitation of meetings between persons harmed by wrongdoing or conflict and persons who caused the harm. This process is centred on restoring the dignity of all persons involved, rather than being centred on blame and punishment.

\section{Teachers}

Teachers are key role models and need to build their competency to respond to problems in the classroom nonviolently, particularly related to student behaviour problems. Currently, teachers often rely on administrators or outside experts to resolve these problems, and, in some cases, school rules require teachers to send problem students to specific administrators without teacher intervention.

Teachers can accept their professional responsibility for assisting students to manage their behaviours and build competency by:

- building relationships with students starting with the first day of contact

- getting to know the students and the family and community in which they live and sharing information about themselves

- changing pedagogy from traditional to discursive by shifting from the lecture style of delivery to a more interactive style, with reciprocal teaching and learning occurring among students and between the teacher and students

- coaching and supporting colleagues who are not able to handle student behaviour problems. Teachers can learn from one another how to handle these problems through a process of shadow coaching. The supporting colleague can act as a facilitator for a conversation between the student and teacher so the relationship can be healed 
- avoiding labels and engaging in restorative conversations. Teachers are prone to giving students labels (e.g., naughty, bad, slow), and those labels stay with the student for long periods of time

- by engaging in restorative conversations, where the problem is separated from the person, teachers learn to respect the dignity of the person while dealing with the problem

- using peacemaking circles to address issues and problems affecting students as a group. Combining peacemaking circles with restorative conversations allows a group of students and a teacher in a classroom to talk about problems in a safe environment where harm, rather than blame, can be the focus and restoring the dignity of all involved the goal.

Using these seven ideas, teachers can:

- develop reciprocal relationships in classrooms, where students are cared for and about and, in turn, respond appropriately to care (Noddings, 1992)

- have high expectations of students (Gay, 2000)

- be prepared to teach each day (Macfarlane, 2004).

With these acquired skills, students and teachers are able to help create a culture of peace in schools and our children will have the foundation for being peaceful citizens and active participants in creating a peaceful society. As a result, schools will be safe, and students and teachers can be free from harm and the threat of harm.

\section{Schools}

Several of the ideas investigated in this research relate to school systems. In order to support a culture of peace and nonviolence, principals need to share power and distribute leadership. These results can be obtained through transformational leadership (Liontos, 1992). The idea of transformational leadership comes from the business world. This type of leadership was characteristic of organisations that had participative decision making and shared power. In contrast, instructional leadership typifies school management. This leadership style is a top down, hierarchical process, where students and teachers are closely monitored.

Transformational leaders are the keepers of the collective vision of the school and engage in reciprocal relationships with teachers, rewarding teachers who improve student learning and holding other teachers accountable. This type of leadership has three goals:
- creating a collaborative professional school culture focused on collective responsibility and continuous improvement

- encouraging teacher development

- building the capacity of teachers to solve problems effectively.

The results of this kind of leadership are: influencing teacher collaboration; and shifting teacher attitudes towards school improvement and pedagogy, which improves student achievement and creates a school culture conducive to caring and learning (Liontos, 1992). Most importantly, school administrators can support and encourage the development of student and teacher competencies to respond to wrongdoing and conflict nonviolently.

Barriers to this process, however, include professionalising and problematising behaviour problems, primarily through hierarchical interference, by:

- encouraging or requiring teachers to send students who are creating problems to a designated expert, usually an administrator

- making more serious problems out of issues that can be handled in the classroom.

Building teacher and student competencies to resolve problems nonviolently is fundamental to creating peaceful schools and developing children into citizens who can participate in creating a sustainable democratic society. Principals are key people in developing student and teacher leadership in this area.

\section{Conclusion}

Traditional approaches to student discipline, even when complemented by restorative processes, have not created safe schools. Initiatives that focus on school suspensions and stand downs or teacher pedagogy, without co-ordinating with one another, have not solved the problems related to student behaviour in schools. Only whole-school reform, based on building healthy relationships, will create a new culture of safety where successful learning can occur (Comer, Haynes, Ben-Avie, \& Joyner, 1996).

However, professional development initiatives aimed at reforming schools often operate in isolation from one another. As a result, the school may have a professional development focused on relationships-based pedagogy, and at the same time be engaged in restorative practices, but without co-ordination and collaboration between the two projects. What is needed is a change in the school culture to bind professional development initiatives together and focus them on common goals.
In order to have a climate of safety in New Zealand schools, we can invoke restorative practices not only as a tool, but also as the philosophical foundation of how to respond to student wrongdoing and conflict. Rather than having administrators be the disciplinarians, students and teachers can be taught how to respond nonviolently to harmful behaviours through such processes as restorative conversations, peer mediation, peacemaking circles, and restorative conferences. In that way building healthy relationships will be at the core of how schools operate and healing broken relationships will guide disciplinary policies.

\section{References}

Braithwaite, J. (2001). Crime in a convict republic. Modern Law Review, 64(1), 11-50.

Cameron, L., \& Thorsborne, M. (2001). Restorative justice and school discipline: Mutually exclusive? A practitioner's view of the impact of community conferencing in Queensland schools. In J. Braithwaite \& H. Strand (Eds.), Restorative justice and civil society (pp. 381-458). Chicago: Cambridge University Press.

Charmaz, K. (2000). Grounded theory: Objectivist and constructivist methods. In N. Denzin \& Y. Lincoln, (Eds.), Handbook of qualitative research (2nd ed., pp. 509-535). Thousand Oaks, CA: Sage Publications.

Comer, J. P., Haynes, N., Ben-Avie, M., \& Joyner, E. (1996). Rallying the whole village: The Comer process for reforming education. New York: Teachers College Press.

Creswell, J. W. (1998). Qualitative inquiry and research design: Choosing among five traditions. Thousand Oaks, CA: Sage Publications.

Gay, G. (2000). Culturally responsive teaching: Theory, research, and practice. New York: Teachers College Press.

Heshusius, L. (1994). Freeing ourselves from objectivity: Managing subjectivity or turning toward a participatory mode of consciousness? Educational Researcher, 23(3), 15-22.

Liontos, L. B. (1992). Transformational leadership (ERIC Digest). Eugene, OR: ERIC Clearinghouse on Educational Management. (ERIC Document Reproduction Service No. ED347636). Retrieved 27 May 2006, from http://www.ericdigests.org/1992-2/ leadership.htm

Macfarlane, A. (2004). Kia hiwa ra! Listen to culture-Māori students' plea to educators. Wellington: New Zealand Council for Educational Research.

Noddings, N. (1992). The challenge to care in schools: An alternative approach to education. New York: Teachers College Press.

Pranis, K., Stewart, B., \& Wedge, M. (2003). Peacemaking circles: From crime to community. St. Paul, MN: Living Justice Press. 
Shaw, M. (2002, September-October). Promoting safety in schools: International experience and action. Paper presented at The Role of Schools in Crime Prevention conference convened by the Australian Institute of Criminology in conjunction with the Department of Education, Employment and Training, Victoria, and Crime Prevention Victoria, Melbourne, Australia.

The Restorative Practices Development Team. (2004). Restorative practices for schools: A resource. Hamilton: University of Waikato, School of Education.

Tillmann-Healy, L. (2001). Between gay and straight: Understanding friendship across sexual orientation. Walnut Creek, CA: Rowman \& Littlefield Publishers, Inc.
Van Maanen, J. (1988). Tales of the field: On writing ethnography. Chicago: University of Chicago Press.

Zehr, H. (1995). Changing lenses. Scottdale, PA: Herald Press.

Zehr, H. (2002). The little book of restorative justice. Intercourse, PA: Good Books.
Note

1 Howard Zehr is recognised by scholars and practitioners in the field of restorative justice as the senior author. His latest book is a wonderful update of his classic book, Changing Lenses. Zehr does a masterful job of condensing the theory of restorative justice into a small book.
Dr Tom Cavanagh is Senior Research Fellow for Te Kotahitanga at the School of Education, University of Waikato. He first arrived in New Zealand in 2004 as a Fulbright Fellow.

Email: cavanaghळwaikato.ac.nz

\section{TOP TITLES FROM NZCER PRESS}

\section{Doing Educational Research: A practitioner's guide to getting started} Carol Mutch

Here is a comprehensive overview of the research process-easy to understand and easy to apply. A "must read" for those starting out on research or beginning to write up their own school-based projects. Also for experienced researchers wanting a handy reference or a "refresher".

Contents include: selecting a research design; reviewing the literature; choosing methods, strategies, and tools; writing proposals; doing the research; analysing the data; writing up the findings.

"Carol Mutch provides the best maps I've encountered for those who use qualitative approaches... She writes extremely well, her headings provide a great directory for research 'travellers', she tells engaging tales of researchers' experiences, and finishes with a comprehensive glossary."
NZCER Press 2005
ISBN 1-877398-01-2
Price: $\$ 39.60$

Anne Meade

\section{Catching the Knowledge Wave? The Knowledge Society and the future of education Jane Gilbert}

Here is a book that challenges traditional educational thinking. In Catching the Knowledge Wave? Jane Gilbert takes apart many long-held ideas about education. She tells us that knowledge is now a verb not a noun-something we $d o$ rather than something we have-and explores the ways our schools need to change to prepare young people to participate in the knowledge-based societies of the future.

The challenge for educators and training providers is how to link into the new structures and build on the opportunities they offer. The author argues that it not enough to simply add new ideas to the old frameworks. We need a completely new framework. We need to deconstruct our existing ideas of knowledge so that we can decide what is worth keeping and then what needs to be done to move our education system from where it is now, to where it needs to be to meet the needs of the knowledge age.

This book is one to argue with, to agree with, to disagree with, but above all it provides a stimulus for vigorous debate about our current education system.

Dr Jane Gilbert is a chief researcher with the New Zealand Council for Educational Research. She has a wide background in teaching at both secondary and tertiary levels.

NZCER Press 2005

ISBN 1-877398-04-7

RRP: $\$ 36.00$
Coaching Leadership: Building educational leadership capacity through coaching partnerships

Jan Robertson

Coaching Leadership is about building leadership capacity in individuals, and in institutions, through enhancing professional relationships. It is based on the importance of maximising potential, and harnessing the ongoing commitment and energy needed to meet personal and professional goals. Based on over a decade of research and development, nationally and internationally, Coaching Leadership brings you the empirical evidence, the principles, and the skills, to be able to develop your own leadership and that of others you work with.

This book:

- challenges you to critically reflect on your leadership and professional relationships

- offers practical activities and exercises

- describes leadership coaching based on reciprocal processes

- seeks to connect theory and practice

provides a basis for workshop activities in coaching, appraisal, and mentoring.

This book comes highly recommended to those professionals committed to lifelong, experiential learning and reflective practice. An essential addition to the professional development programme.

Jan Robertson is an associate professor and assistant dean in the School of Education, at the University of Waikato, Hamilton, New Zealand. She is director of the Educational Leadership Centre and studies and teaches about coaching and mentoring, action research and leadership development. Her work is widely respected both in New Zealand and overseas.

"Jan Robertson's splendid book not only advocates articulately for the necessity of leadership coaching, but sets out practically what good coaching can, and should, look like." Andy Hargreaves, Boston College
NZCER Press 2005
ISBN 1-877398-02-0
Price: $\$ 39.95$

\section{AVAILABLE FROM NZCER SALES}

Contact: sales@nzcer.org.nz

Fax: 04 384 7933. Internet: www.nzcer.org.nz 